\title{
Original Article \\ Comparing software piracy in South Africa and Zambia using social cognitive theory
}

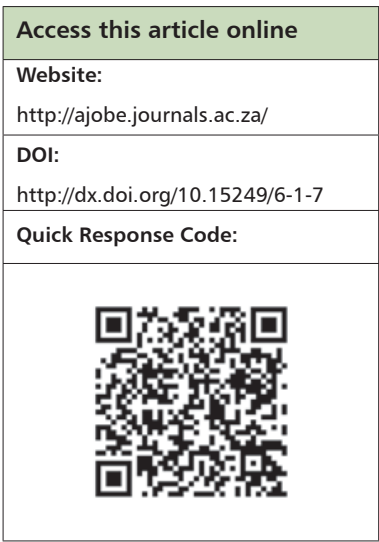

Address for correspondence: Prof. Andrew Thatcher, Psychology Department, University of the Witwatersrand, School of Human and Community Development, WITS, 2050,

South Africa.

E-mail: Andrew.Thatcher@wits.

ac.za

\section{Andrew Thatcher, Mary Matthews}

Psychology Department, University of the Witwatersrand, School of Human and Community Development, WITS, 2050, South Africa

\section{ABSTRACT}

This study examines cross-national differences in relation to software piracy between a Zambian and a South Africa student sample on components of Bandura's Social Cognitive Theory. The sample was selected based on the vastly different software piracy rates between Zambia (82\%) and South Africa $(35 \%)$ and the fact that software piracy rates are higher amongst student groups. The questionnaire was composed of previously developed scales measuring attitudes, social norms, intentions, incentives, deterrents, self-efficacy, and moral disengagement within the context of software piracy. The sample was gathered from one University in Zambia $(N=69)$ and one in South Africa $(N=71)$ in the students' final and penultimate years of study. Statistical differences were found between the two samples on the attitudes and social norms scales, with the South African sample having more positive attitudes and more favourable social norms towards software piracy than the Zambian sample. In terms of the theoretical model, attitudes, social norms and self-efficacy predicted software piracy intentions in both samples.

Key words: Moral disengagement, piracy intentions, software piracy, social cognitive theory, self-efficacy, social norms, South Africa, Zambia

\section{INTRODUCTION}

Social Cognitive Theory (SCT) views people as self-organising and self-regulating rather than merely reacting to the environment or driven by subconscious motives. As such, Bandura (1986) argues that SCT is more sensitive to individual differences than to cultural differences. Central to understanding deviant behaviour within SCT is the notion of self-regulatory mechanisms, more specifically deficient self-regulation (LaRose and Kim, 2007) and moral disengagement (Bandura, Barbaranelli, Caprara and Pastorelli, 1996). Although Bandura (1986) did not explicitly identify structural relationships within the theory, research on the use of SCT to promote healthy behaviours has led to the identification of some of the major social cognitive determinants of human behaviour, including: self-efficacy, attitudes, social norms, deterrents and incentives, and intentions - referred to as proximal goals in SCT (Bandura, 2004). Some of the processes of SCT (specifically attitudes, self-efficacy, and social influences) have some similarities with normative beliefs, perceived behavioural control, and social norms found in the theory of planned behaviour (Ajzen, 1991). Where SCT adds something different to the theory of planned behaviour is in its treatment of antisocial behaviour through the concept of moral disengagement. Software piracy has been characterised as an instance of antisocial behaviour (Eining and Christensen, 1991). Unlike other examples of antisocial behaviours such as violent crime or physical aggression, software piracy behaviours are perceived to be relatively harmless (Siponen and Vartiainen, 2007) since they do not result in direct, grievous physical harm to others, although the economic harm to software companies may be extremely large.

Software piracy is defined as the copying or distribution of software applications on personal computers, servers, desktops, laptops, and other portable electronic devices, without the permission of the software author/s or organisation who owns the copyright or intellectual property. Software piracy (Cronan and Al-Rafee, 2008) has also been referred to in the literature as unauthorised copying or distribution of software (Siponen and Vartiainen, 2005) or softlifting (Rahim, Rahman, and Seyal, 2000). 
Software piracy is an interesting business ethics issue to study because of the strongly divergent views between software developers/distributors /who hold the view that software piracy infringes on intellectual property and stifles development and creativity) and large sections of the software consumer market (who hold that software should be cheaper and more freely available to stimulate growth and development). In this study we examine data from two countries in Africa, selected because one is on the list of countries with the twenty lowest rates (South Africa at 35\%) and the other on the list of countries with the twenty highest rates (Zambia at $82 \%$ ) of software piracy in 2010. This study examines a selection of SCT variables to determine: (a) whether there are any significant differences between the two samples on any of the SCT variables; (b) whether there are any significant differences in the correlations of the SCT antecedents with software piracy intentions [Figure 1]; and (c) whether there are any differences in the significant predictors of software piracy intentions.

\section{SOFTWARE PIRACY}

Software piracy is not a single act, but manifests at different levels of severity. Crittenden, Robertson and Crittenden (2007) outline five levels of severity from highest to lowest: (1) Large-scale counterfeiting of software for commercial gain; (2) hard-disk loading when selling software bundled with hardware; (3) sharing or downloading from illegal websites such as illegal peer-to-peer file-sharing portals; (4) loading on more computers than the licence allows; and (5) copying or allowing others to make a copy of legally purchased software. The intentions and legal culpability would be different depending on the severity of the software piracy.

Software piracy is illegal because it violates intellectual property rights (Gopal and Sanders 2000) and infringes copyright laws (Moores and Dhillon, 2000). Despite legislation, software piracy is globally prevalent, costing the software development and distribution industry an estimated US $\$ 58.8$ billion in 2010 alone (Business Software Alliance 2011). Globally the software piracy rate stands at approximately $42 \%$ for 2010 , up from $41 \%$ in 2008 (Business Software Alliance 2011). This figure implies that for every ten copies of computer software in use worldwide, approximately six have been obtained legally and more than four have been obtained illegally. Regionally, the problem is

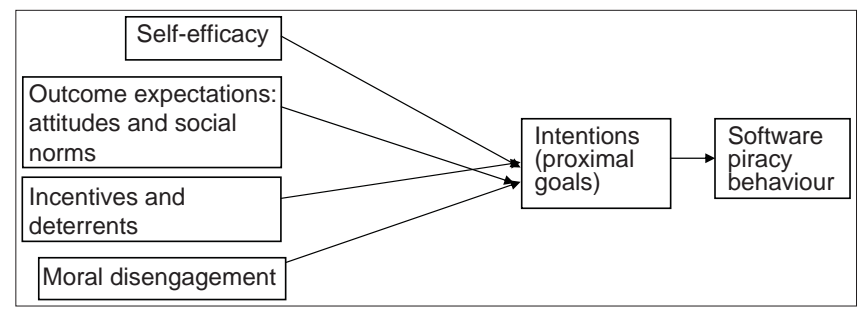

Figure 1: Model of SCT under investigation in this study most extreme in Central and Eastern Europe (64\%), Latin America (64\%), Asia-Pacific (60\%), and Middle East/Africa (58\%). Critiques of these figures are numerous (e.g. see Png, 2010) so one must be cautious in placing too much value on the Business Software Alliance reports, given that for many developing countries the figures are estimates and there are a large number of assumptions that are made in computing these statistics. These include the assumption that every computer has the same number of software applications and that people can afford to pay for all the software applications on their computers.

The simple argument that is used to justify software piracy is that software is perceived to be too expensive and therefore people are "forced" into piracy in order to get access to the software that enables them to do their work (Gopal and Sanders, 2000). This view is supported by the Business Software Alliance's (2011) observation that more illegal software than legal software is installed in emerging economy countries. However, Crittenden et al . (2007) identify several other reasons for software piracy, including wanting to preview software before purchasing, only wanting one aspect of the software and not the entire suite, not having access to a place to legitimately purchase the software, showing off security "cracking" skills to friends and colleagues, and using software to benefit community projects. Further, a simple economic argument does not explain why software piracy is relatively high in wealthy countries such as Saudi Arabia (52\%) or Iceland (49\%), but relatively low in poorer countries such as South Africa (35\%), the Czech Republic (37\%), or Slovakia (43\%) (Business Software Alliance 2011).

While economic factors are certainly important, other researchers (Bagchi, Kirs and Cerveny, 2006; LaRose, Lai, Lange, Love and Wu, 2005; Shin, Gopal, Sanders and Whinston, 2004) contend that individual, social and psychological factors also play a significant role in understanding software piracy behaviour. A review of the software piracy literature reveals three primary foci for the research. The first focus has been to understand the individual determinants of software piracy by exploring how software piracy varies with demographic factors such as age, and gender, socioeconomic status and frequency of computer use on software piracy intentions and behaviour (Sims, Cheng and Teegen, 1996; Rahim et al., 2000; Hinduja, 2003). The second focus has been to consider the impact of social contextual variables including interpersonal interactions (Glass and Wood, 1996; Tang and Farn 2005), industry sector (Mishra, Akman and Yazici, 2007), organisation culture (Lending and Slaughter 1999) and national culture and legal factors (Al-Jabri and Abdul Gader, 1997; Husted, 2000; Robertson, Gilley, Crittenden and Crittenden, 2008).

The third focus has been to use theoretical frameworks to understand software piracy. The earliest studies taking this 
focus concentrated on aspects such as general attitudes towards the morality of unauthorised copying (Swinyard, Rinne and Kau, 1990) and attitudes and biographical descriptors (Shim and Taylor, 1991; Simpson, Bannerjee and Simpson, 1994; Solomon and O'Brien, 1991; Taylor and Shim, 1993). More recent investigations have attempted to understand some of the psychological theories and mechanisms underpinning the behaviours of software piracy, including moral development (Kini, Ramakrishna and Vijayaraman, 2003), the theory of reasoned action (Eining and Christensen, 1991; Rahim et al. 2001; Seale, Polakowski and Schneider, 1998; Shin et al., 2004; Woolley and Eining, 2006), the theory of planned behaviour (Chang, 1998; Peace et al., 2003; Cronan and Al-Rafee, 2008), the theory of interpersonal behaviour (Limayem et al., 2004), deindividuation theory (Hinduja, 2008), neutralisation theory (Hinduja, 2007), social learning theory (Higgins and Makin, 2004), ethical decision-making (Gopal and Sanders, 1998; Thong and Yap, 1998), personality factors (Wang, Zhang, Zang and Ouyang, 2005), and equity theory (Glass and Wood, 1996).

\section{Software piracy and SCT}

A theoretical approach that has recently gained attention in attempts to understand the unauthorised downloading of software and music (LaRose and Kim, 2007; LaRose et al., 2005) has been Bandura's (1986) SCT. LaRose et al. (2005) looked at the influence of outcome expectations, self-efficacy, deficient self-regulation, and moral justification (one aspect of moral disengagement) on file-sharing behaviour. LaRose and Kim (2007) looked at the influence of outcome expectations, self-efficacy, habits (past behaviours), and deficient self-regulation on unauthorised music downloading behaviour. Both these studies found support for the SCT aspects as predictors of unauthorised downloading behaviour. The following elements of SCT were investigated in this study: Software piracy self-efficacy, software piracy outcome expectations (i.e. attitudes and social norms), incentives and deterrents to pirate software, moral disengagement with respect to software piracy, and intention to pirate software [Figure 1]. Software piracy behaviour was not investigated in this study given the concern that people would be less likely to respond if they were asked about performing potentially illegal acts.

\section{Self-efficacy}

At the heart of SCT is personal efficacy, the belief that one can produce desired changes and effects through one's actions (Bandura, 2006). Competent functioning requires both skills and self-belief. Perceived self-efficacy, however, is not concerned directly with the skills one has but with the judgments of what one can do with these skills (Bandura, 2006). In the theory of planned behaviour, the self-efficacy construct is subsumed in the notion of perceived behavioural control (Ajzen, 1991). In the literature on software piracy, perceived behavioural control has been included in models predicting software piracy intentions or behaviours as defined in the theory of planned behaviour (Cronan and Al-Rafee, 2008). Empirical evidence of the relationship between perceived behavioural control and software piracy intentions is mixed, with Cronan and Al-Rafee (2008) confirming the centrality of the relationship and Peace, Galleta and Thong (2003) finding that other variables were more important.

\section{Outcome expectations}

Outcome expectations are anticipatory judgments about the likely consequences of actions referring specifically to attitudes and subjective social norms as they have traditionally been defined in the theory of planned behaviour (Ajzen, 1991). Attitudes are defined in terms of the degree of favourable evaluation towards a behaviour (i.e. in the context of this study this means a respondent holds an attitude that software piracy is acceptable). Subjective social norms are defined as perceived social pressures and one's motivation to comply with those social pressures (Bandura, 2004). Generally, outcome expectations in the software piracy literature have been researched under the attitudes and subjective (or social) norms labels (Eining and Christensen, 1991) typical to the theory of planned behaviour. Some research has shown that both attitudes and social norms are significantly related to software piracy intention (Peace et al., 2003), while other research found that while attitudes were a significant predictor of intention, subjective norms were not (Cronan and Al-Rafee 2008). Also within the theory of planned behaviour, Chang (1998) found that subjective norms had a significant indirect effect (whereas perceived behavioural control had a direct effect) on intentions to pirate software.

\section{Incentives and deterrents}

Incentives and deterrents refer to the perceived objective contextual and environmental factors that render behaviours easier or more difficult to execute (Limayem et al., 2004). These refer to the specific situations in which individuals find themselves and the systemic factors embedded in the societal systems in which they operate, which could serve either as facilitating or obstructing factors in the formation of intentions. Conceptually, the facilitating conditions construct proposed by Triandis (1977) in his theory of interpersonal behaviour most closely resembles Bandura's (1986) notion of incentives and deterrents. In the software piracy literature, easy access to pirated software and the ready availability of illegal software products are cited as two situational facilitators that inform software piracy behaviour (Siponen and Variainen, 2005), with legal and economic realities impacting software piracy at a broader systemic level. Limayem et al. (2004) incorporated the elements of inadequate institutional measures to curb software piracy and access to resources as facilitating conditions likely to affect software piracy behaviour. Limayem et al . (2004) found that these facilitating conditions significantly increased software piracy behaviour. 


\section{Moral disengagement}

When individuals choose to override the influence of their internal self-sanctions due to favourable outcome expectations and the facilitating factors operating in their contexts, they distance themselves from the reprehensible consequences of their behaviour through moral disengagement. Bandura (1986) identified eight mechanisms of moral disengagement through which individuals could justify their behaviour. These mechanisms are clustered into four groups corresponding to the four major points in the self-regulatory process at which internal moral control may be disengaged from moral conduct [Figure 2].

In relation to the reprehensible behaviour itself, the three disengagement mechanisms of moral justification, advantageous comparison and euphemistic labelling are relevant. The displacement and diffusion of responsibility are two mechanisms of moral disengagement activated when the relationship between reprehensible actions and their effects is obscured or distorted. The third point at which moral disengagement can occur is in relation to the consequences of reprehensible acts. The manner in which self-deterring reactions are weakened in this context is through the minimisation, ignoring or misconstrual of the consequences of reprehensible actions. The final two moral disengagement mechanisms occur at the point of the consequences experienced by the recipients or victims of reprehensible deeds and are classified as dehumanisation and attribution of blame (Bandura 1986). The four major points and the eight mechanisms are given in the Table 1 together with an example relevant to software piracy.

In a study on peer-to-peer file sharing (primarily music file sharing) LaRose et al. (2005) found that the perceived moral acceptability (i.e. moral justification) was a significant predictor of downloading activity. Similarly, in a study of music downloading, one of the eight mechanisms of moral disengagement (i.e. moral justification) was included in a social cognitive model for explaining downloading intention (LaRose and Kim, 2007). The findings of their study suggested a significant, direct and positive causal relationship between moral justification and deficient self-regulation (diminished self-control), which, in turn,

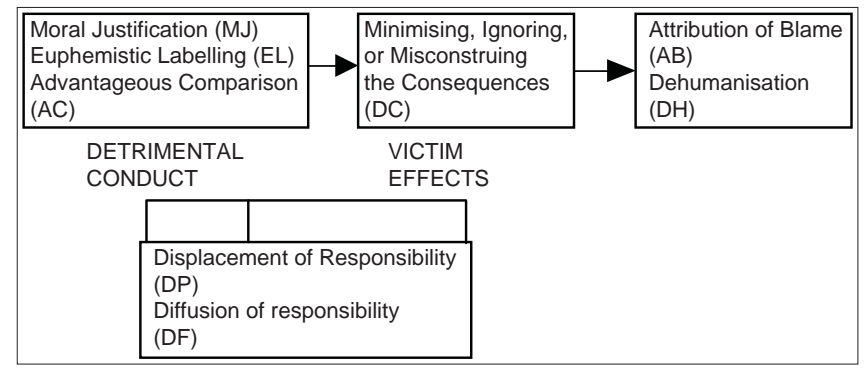

Figure 2: Points at which moral disengagement occurs (modified from Bandura (1986); p. 376) had a significant, direct and positive causal relationship with intention to continue downloading music.

\section{Intentions}

Intentions refer to the perceived likelihood that a person will engage in a specific behaviour. In SCT, the process of arriving at what one intends to do (i.e. the intention) and the course of action one actually follows (i.e. the actual behaviour) are separate events (Bandura, 1986). The traditional concept of intentions in the theory of planned behaviour (Ajzen, 1991) corresponds with Bandura's (2004) notion of proximal or short-term goals. In the theory of planned behaviour (Ajzen, 1991) intentions existed as an immediate antecedent to behaviour and were believed to be the strongest predictors of behaviour.

\section{Cross-national comparisons of software piracy}

While research has explored psychological mechanisms of software piracy in a number of different countries (e.g. Brunei (Rahim et al., 2001), China (Wang et al., 2005), Finland (Siponen and Vartianen, 2005), Hong Kong (Moores and Dhillon, 2000), Saudi Arabia (Al-Jabri and Abdul-Gader, 1997), Singapore (Thong and Yap, 1998), Thailand (Kini et al., 2003), and Turkey (Mishra et al., 2007)I, there are very few direct cross-nation comparison studies. Swinyard et al. (1990) examined the influence of cultural conceptions of morality on software piracy behaviour in a Singaporean and a US sample. Swinyard et al. (1990) found that while knowledge of software piracy laws was higher in the Singaporean sample, attitudes towards software piracy were also more favourable, as were software piracy intentions. These differences were attributed to different cultural norms towards copyright. Cho and Eining (1997) found that their US sample held less favourable attitudes towards software piracy than the Korean and Chinese samples. Similarly, Ballantine (2000) found that the sample from Malaysia was less likely than a sample from New Zealand to perceive that software piracy would cause harm.

Other cross-national studies of software piracy have focused on economic indicators, but at the level of an entire country rather than at an individual level. For example, Shin et al. (2004) found that GDP per capita was inversely associated with piracy rates across various countries. Husted (2000) found similar results when looking at per capita GNP. Similarly, Robertson et al. (2008) found that economic growth, direct foreign investment, Internet usage, and development assistance were all related to software piracy rates in Latin America. Since Zambia's (US\$1 400) per capita GDP was far lower than South Africa's (US\$10 300) per capita GDP in 2009 we might expect software piracy intentions to be higher in Zambia than in South Africa. On the other hand, Traphagan and Griffith (1998) and Bagchi et al. (2006) found that there was a poor relationship between per capita GDP and software 
piracy rates. Traphagan and Griffith (1998) pointed to the importance of cultural norms in determining whether software piracy was perceived as an illegal activity or not. Gopal and Sanders (1998) found that software piracy rates were inversely related to the size of the domestic software industry, suggesting that people were more likely to pirate software when it was more difficult to legally purchase the originals (i.e. that software piracy rates would be higher in Zambia due to the significantly larger software industry in South Africa). Of course, in relatively poorer countries (such as Zambia) there are fewer people who are able to purchase computer hardware (Husted, 2000). Since there is no need to pirate software if one does not have access to the hardware in the first place, one might actually expect software piracy intentions in Zambia to be lower.

Shin et al. (2004) found a significant relationship between a national collectivistic culture and the national software piracy rate, with people in a high collectivistic country being more likely to pirate software, with the influence being even stronger for lower-income countries. Similarly, Kovacic (2007) found that countries with high levels of economic development and strong intellectual property laws also had lower software piracy rates (with economic factors explaining more variance than legal factors). In addition, countries that have a higher masculine, collectivist, and greater power-distance culture would be more likely to pirate software. Unfortunately, while Hofstede's culture dimensions (i.e. collectivism, masculinity, and power distance) have been extensively studied in South Africa, there are no comparable national measures for Zambia. A number of other studies have invoked culture as an important determinant of software piracy intentions within groups in the same country (Al-Jabri and Abdul Gader, 1997; Lending and Slaughter, 1999; Shim and Taylor, 1991). Shim and Taylor (1991) invoked organisational culture as an explanation for differential software piracy perceptions between university and business managers, with the university sample having more favourable perceptions towards software piracy. Shim and Taylor (1991) argued that university managers were less closely managed and were incentivised more by personal goals rather than organisational goals.

The International Data Corporation (2009) lists several reasons for the prevalence of software piracy in Africa. These reasons include ineffectual or non-existent intellectual property laws, a poor understanding of what constitutes software piracy, and the social acceptance of software piracy as a reasonable behaviour. South Africa has a far more sophisticated intellectual property law landscape than Zambia, although the International Data Corporation (2009) argues that South Africa's enforcement of the law and penalties for copyright infringements is ineffectual. In South Africa, the government and the South African branch of the Business Software Alliance have been relatively active in running anti-piracy campaigns to enhance awareness around software piracy. There have been no equivalent campaigns in Zambia and no significant Business Software Alliance presence in that country. This study seeks to explore aspects of the social acceptance of software piracy in these two countries. Students were used for the comparison samples in both countries, as software piracy has been demonstrated as being high amongst student groups (Cronan and Al-Rafee, 2008; Hinduja, 2007; Liang and Yan, 2005; Moores and Dhillon, 2000; Sims et al., 1996; Woolley and Eining, 2006). In addition, Van Belle, MacDonald and Wilson (2007) found that more than $70 \%$ of their South African student sample had pirated software at least once, suggesting that software piracy was highly prevalent amongst this population.

In order to explore, from a psychological theory perspective, why Zambia and South Africa have such different software piracy rates we looked at the following hypotheses within the framework of Social Cognitive Theory (Bandura, 1986) dimensions [Figure 1] with special emphasis on cross-nation comparisons:

- H1. The Zambian sample would have significantly higher attitudes, social norms, moral disengagement, self-efficacy beliefs, perceptions of incentives, and intentions and significantly lower deterrents towards software piracy than the South African sample.

- H2. There would be no significant differences in the SCT variables' relationships between (a) attitudes, (b) social norms, (c) self-efficacy beliefs, (d) incentives and deterrents, and (d) moral disengagement towards intentions to pirate software in the South African and Zambian samples.

- H3. The best predictors of intention to pirate software would be the same in the South African and Zambian samples.

\section{MATERIALS AND METHODS}

\section{Sample}

Zambia and South Africa were selected because of a) their differing software piracy rates (South Africa having one of the lowest and Zambia having one of the highest software piracy rates in the World), b) their relative geographical proximity, and c) the medium of instruction being English at both universities, as the questionnaire was in English and the majority of software distributed in these countries was in English. Students were selected because previous research has argued that software piracy was more prevalent amongst student groups (Sims et al., 1996; Siponen and Vartiainen, 2005; Van Belle et al., 2007) and undergraduate students were selected because Sims et al. (1996) found that graduate students were less likely to pirate software. In addition, Gupta, Gould and Pola (2004) found that software piracy was higher amongst younger people. 
The South African sample $(\mathrm{N}=71)$ consisted of 37 males and 34 females all aged between 18 and 28 years old. There were 44 students in their second year and 27 students in their third year of study (bachelor degrees in Economics were three-year degrees in South Africa). There were 26 black African, 12 Indian, 31 white, and 1 coloured student.

In the Zambian sample $(\mathrm{N}=69)$ there were 57 males and 12 females. There were $53(77 \%)$ students aged between 18 and 28 years old, with 12 students aged 29 to 38 and 4 students aged 39 to 49 years old. There were 27 students in third year and 42 in their fourth year of study (bachelor's degrees in Economics were four-year degrees in Zambia). All respondents in the Zambian sample were black African students.

Foreign students at each university (e.g. non-Zambian students at the Zambian university) were excluded from the sample.

\section{Measures}

In the general instructions a definition of software piracy was provided to ensure that all respondents were clear as to what constituted software piracy.

\section{Biographical information}

General biographical information (i.e. gender, age, race, and year of study) as well as information on computer use (i.e. years of use and number of hours per day) and the level of use of different computer applications highly related to software piracy (i.e. computer games and the Internet) was collected.

\section{Outcome expectations}

Attitudes (4 items) and social norms (3 items) were measured using scales developed by Peace et al. (2003). Attitudes (Cronbach alpha $=.81$ in the current study) were measured on semantic differential scales, where respondents were instructed to circle a value between 1 and 5 between two anchor words (e.g. whether software piracy is "foolish" or "wise", "pleasant" or "unpleasant", etc.). Social norms (Cronbach alpha $=.67$ in the current study) were measured on a five-point Likert-type scale, where respondents were asked to indicate their agreement or disagreement with statements regarding people important to them.

\section{Self-efficacy}

Self-efficacy (three items) was measured using an adapted version of LaRose et al.'s (2005) scale. LaRose et al.'s original scale was developed to assess self-efficacy towards online file sharing. The three items were therefore adapted by replacing "file sharing" with the words "software piracy". Self-efficacy (Cronbach alpha $=.77$ in the current study) was measured on a five-point Likert-type scale, where respondents were asked to indicate their agreement or disagreement with statements regarding confidence in their ability to pirate software.

\section{Incentives and deterrents}

The incentives (13 items) and deterrents (five items) scales were self-developed based on Bandura's (1986) definitions and pilot-tested on a separate sample of 217 respondents in banking, production, and information technology organisations. Incentives (Cronbach alpha $=.76$ in this study) and deterrents (Cronbach alpha $=.76$ in this study) were measured on a five-point Likert-type scale where respondents were asked to indicate their agreement or disagreement with statements regarding issues that would encourage or discourage software piracy.

\section{Moral disengagement}

The moral disengagement scale (20 items) was also self-developed based on Bandura's (1986) definitions of the eight mechanisms. The first version of the scale had 40 items that was pilot-tested on a separate sample of 402 respondents in banking, advertising, and information technology organisations. Item and factor analyses were used to reduce the scale to a 20 -item scale, which was then pilot-tested on another sample of 217 respondents in banking, production, and information technology organisations. A confirmatory factor analysis supported the four-factor structure of Bandura's (1986) moral disengagement mechanisms. Moral disengagement (Cronbach alpha $=.87$ in this study) was measured on a five-point Likert-type scale, where respondents were asked to indicate their agreement or disagreement with statements regarding statements related to the morality of software piracy [Table 1].

\section{Intentions to pirate software}

Intentions to pirate software (three items) were measured using a scale developed by Peace et al. (2003). Intentions (Cronbach alpha $=0.87$ in the current study) were measured on a five-point Likert-type scale, where respondents were asked to indicate their agreement or disagreement with statements related to future behavioural intentions to pirate software.

\section{Procedure}

One hundred and fifty questionnaires were distributed in two senior undergraduate-level Economics classes at the two universities by one of the researchers. Students who volunteered to participate completed the questionnaire in their own time and placed completed questionnaires in a sealed box found in each Economics Department's administration office. The response rates were reasonable and similar for each sample (a response rate of $47 \%$ for the South African sample and $46 \%$ for the Zambian sample).

\section{Ethics}

Prior to collecting data, permission was granted from 
the University's Human Research Ethics Committee (non-medical). Participation was voluntary and informed consent was obtained by a cover letter on the front page of the questionnaire. No personal identifying information was requested, therefore assuring anonymity and confidentiality. Feedback was given to students once the research was completed by placing a summary report on their class notice boards.

\section{Analysis}

Normality tests found no instances of normality issues with any of the variables. Comparisons between the South African and Zambian samples on computer experience and on each of the SCT variables were conducted via t-tests. Cohen's d was calculated to determine the effect size where there were significant differences. Effect sizes of 0.20-0.49 are considered small, 0.50-0.79 are considered medium, and 0.80 are higher are considered large (Huck, 2004). The relationships between the SCT antecedent variables and software piracy intentions were assessed via Pearson's correlations. Comparisons on the strength of the relationships were conducted via Fisher's Z-test, which essentially transforms the correlations $(\mathrm{r})$ into normally distributed scores for direct comparison. Determining which variables were the best predictors of software piracy intentions was conducted using multiple linear regression. To test whether these two multiple regressions were significant for each sample, the model was tested again with the country entered as a moderating variable in a moderated multiple linear regression. The condition index established no problems with multicollinearity in any of the regression models.

\section{RESULTS}

\section{Differences between the Zambian and South African samples on computer experience}

The South African sample had used computers for significantly longer (i.e. most often between 15 and 20 years) than the Zambian sample (i.e. most often between 5 and 10 years) [Table 2]. Similarly, the South African sample had used the Internet more frequently per week than the Zambian sample. The Zambian sample was more likely to use the Internet only once a week and the South African sample more likely to use the Internet every day of the week. The Cohen's d effect sizes (only for the significant differences) were all moderate to large.

\section{Differences between the Zambian and South \\ African samples on SCT variables}

Statistically significant differences were found between the Zambian and South African samples on the two outcome expectations variables (i.e. attitudes and social norms). The Zambian respondents indicated that they held significantly less favourable attitudes towards software piracy and that

\begin{tabular}{|c|c|}
\hline Mechanism & Examples \\
\hline \multicolumn{2}{|l|}{ Reprehensible acts } \\
\hline Moral justification & $\begin{array}{l}\text { Software is too expensive, therefore one is justified in making unauthorised copies } \\
\text { for oneself. }\end{array}$ \\
\hline Advantageous comparison & $\begin{array}{l}\text { Making unauthorised copies of software is not the same as stealing a copy from a } \\
\text { store. }\end{array}$ \\
\hline Euphemistic labeling & Making unauthorised copies of software is the same as borrowing it. \\
\hline \multicolumn{2}{|c|}{ Between the reprehensible action and its effects } \\
\hline Displacement of responsibility & A person in authority said that it was alright to make unauthorised copies. \\
\hline Diffusion of responsibility & Everyone else is making unauthorised copies. \\
\hline \multicolumn{2}{|l|}{ Consequences of reprehensible acts } \\
\hline $\begin{array}{l}\text { Minimising, ignoring or misconstruing } \\
\text { consequences }\end{array}$ & $\begin{array}{l}\text { Software companies still make so much money that a single unauthorised copy } \\
\text { makes little difference. }\end{array}$ \\
\hline \multicolumn{2}{|c|}{ Consequences experienced by recipients/victims } \\
\hline Dehumanisation & $\begin{array}{l}\text { Software companies are blood-suckers who drain as much money as possible out of } \\
\text { the public. }\end{array}$ \\
\hline Attribution of blame & It is the fault of software companies because their software protection is poor. \\
\hline
\end{tabular}

\begin{tabular}{|c|c|c|c|c|c|c|c|c|}
\hline \multirow[t]{2}{*}{ Scale 1-5 } & \multicolumn{3}{|c|}{ South Africa } & \multicolumn{3}{|c|}{ Zambia } & \multirow[t]{2}{*}{ t test } & \multirow[t]{2}{*}{ Cohen's c } \\
\hline & $N$ & $M$ & $S D$ & $N$ & $M$ & $S D$ & & \\
\hline Computer usage in years & 71 & 3.55 & 0.81 & 69 & 2.43 & 0.79 & $8.23 * *$ & 1.35 \\
\hline Computer usage per day & 70 & 1.04 & 0.20 & 67 & 1.11 & 0.33 & -1.65 & \\
\hline $\begin{array}{l}\text { Computer games use, hours } \\
\text { per week }\end{array}$ & 70 & 1.87 & 1.10 & 68 & 2.12 & 0.89 & -1.44 & \\
\hline Internet use hours per week & 70 & 3.51 & 0.86 & 69 & 3.02 & 0.75 & $3.54 * *$ & 0.58 \\
\hline
\end{tabular}

${ }^{*} P<.01 * P<.05$ 
the social norms were significantly less conducive to software piracy [Table 3]. The Cohen's d effect sizes were all small.

Since moral disengagement is a concept unique to SCT, the four points in the self-regulatory process were examined more closely. Only moral disengagement at the point of the reprehensible behaviour was significantly different, with the South African sample more likely to morally disengage. The effect size was small [Table 4].

Incentives and deterrents form the basis for the social context of the respondents. The individual items were therefore examined separately in Table 5. The Zambian sample scored higher only on the intrinsic incentive and the legal deterrent - both small effect sizes. The South African sample scored higher on the extrinsic incentives, monetary reward and reciprocal exchange, some of these with medium effect sizes.

\section{Relationships with software piracy intentions}

In both the Zambian and the South African samples the correlations between the primary independent variables and software piracy intentions were statistically significant [Table 6], except for incentives and deterrents and moral disengagement in the Zambian sample. However, the Z-test results revealed no differences between the two countries' correlations.

\section{Comparing predictors of intentions to pirate software}

In both the Zambian $\left(\mathrm{R}^{2}=.64\right)$ and the South African $\left(\mathrm{R}^{2}=.66\right)$ samples attitudes, social norms, and self-efficacy were the only significant predictors of software piracy intentions, although with slightly different patterns, but explaining a good proportion of the variance in intentions. In the South African sample, attitudes explained the most variance in software piracy intentions [Table 7], whereas in the Zambian sample social norms explained the most variance [Table 8]. In the moderated multiple linear regression model the addition of 'country' as a moderating variable did not yield a significant change in $\mathrm{R}^{2}$ nor did the addition of the interaction terms. Any differences based on country were therefore non-significant.

\section{DISCUSSION}

\section{Comparing the Zambian and South African samples on the SCT variables}

While there were more positive attitudes towards software piracy and more favourable social norms towards software piracy in the South African sample, this did not translate into higher software piracy intentions [Table 3]. This is consistent with Al-Jabri and Abdul-Gader (1997) and Al-Rafee and Cronan (2006), who found that students held more favourable attitudes towards pirating software if their peers supported their behaviour. Swinyard et al. (1990) and Cho and Eining (1997) also found that attitudes towards piracy differed at a national level. The fact that the other psychological aspects (i.e. self-efficacy, incentives and deterrents, moral disengagement, and intentions) were not statistically different suggests that there may be other factors in the social contexts that serve to reduce software piracy intentions. A closer examination of the incentives and deterrents (one part of the social context) provides some insight. Respondents in the Zambian sample indicated they were more likely to consider

\begin{tabular}{|c|c|c|c|c|c|c|c|c|}
\hline & \multicolumn{3}{|c|}{ South Africa } & \multicolumn{3}{|c|}{ Zambia } & \multirow[t]{2}{*}{$t$ test } & \multirow[t]{2}{*}{ Cohen's d } \\
\hline & $N$ & $M$ & $S D$ & $N$ & $M$ & $S D$ & & \\
\hline Self-efficacy & 70 & 8.14 & 3.10 & 69 & 7.22 & 3.33 & 1.70 & \\
\hline Attitudes & 68 & 11.03 & 3.39 & 67 & 9.75 & 3.54 & $2.15^{*}$ & .37 \\
\hline Social norms & 69 & 10.10 & 2.96 & 68 & 9.06 & 3.05 & $2.03^{*}$ & .35 \\
\hline Incentives & 71 & 39.72 & 7.51 & 64 & 37.78 & 7.09 & 1.58 & \\
\hline Deterrents & 70 & 13.01 & 4.02 & 67 & 13.31 & 3.67 & -0.46 & \\
\hline $\begin{array}{l}\text { Moral } \\
\text { disengagement }\end{array}$ & 69 & 55.35 & 11.49 & 61 & 52.07 & 11.55 & 1.62 & \\
\hline $\begin{array}{l}\text { Piracy } \\
\text { intentions }\end{array}$ & 69 & 10.12 & 3.58 & 68 & 10.04 & 3.63 & 1.55 & \\
\hline
\end{tabular}

**P $<.01 * P<.05$

Table 4: Means and $t$-test results for the South African and Zambian samples on the moral disengagement stages

\begin{tabular}{|c|c|c|c|c|c|c|c|c|}
\hline \multirow[t]{2}{*}{ Scale 1-5 } & \multicolumn{3}{|c|}{ South Africa } & \multicolumn{3}{|c|}{ Zambia } & \multirow[t]{2}{*}{$t$ test } & \multirow[t]{2}{*}{ Cohen's d } \\
\hline & $N$ & $M$ & $S D$ & $N$ & M & $S D$ & & \\
\hline At the point of the reprehensible behaviour & 69 & 3.09 & 0.62 & 69 & 2.86 & 0.61 & $2.21 *$ & 0.38 \\
\hline Between reprehensible behaviour and consequences & 69 & 2.35 & 0.73 & 69 & 2.26 & 0.77 & 0.73 & \\
\hline At the point of the consequences & 69 & 2.65 & 0.86 & 69 & 2.43 & 1.01 & 1.37 & \\
\hline At the point of the victim & 69 & 2.81 & 0.68 & 69 & 2.72 & 0.75 & 0.75 & \\
\hline
\end{tabular}

$* * P<.01 * P<.05$ 
Table 5: Means and t-test results for the South African and Zambian samples for incentives and deterrents

\begin{tabular}{|c|c|c|c|c|c|c|}
\hline & \multicolumn{3}{|c|}{ South Africa } & \multicolumn{3}{|c|}{ Zambia } \\
\hline & $\mathbf{N}$ & M & $N$ & M & $\boldsymbol{t}$ & Cohen's d \\
\hline \multicolumn{7}{|l|}{ Incentives } \\
\hline People pirate computer software because it relieves boredom & 71 & 2.18 & 69 & 2.42 & -1.20 & \\
\hline People pirate computer software because it gives them satisfaction & 71 & 2.76 & 68 & 3.26 & $-2.50^{*}$ & 0.42 \\
\hline $\begin{array}{l}\text { People pirate computer software because the people who are important to } \\
\text { them do not think it is wrong }\end{array}$ & 71 & 2.92 & 68 & 2.75 & 0.80 & \\
\hline $\begin{array}{l}\text { People pirate computer software because their behaviour is socially } \\
\text { rewarded }\end{array}$ & 71 & 2.97 & 68 & 3.12 & -0.77 & \\
\hline $\begin{array}{l}\text { People pirate computer software because other people put pressure on } \\
\text { them to do so }\end{array}$ & 71 & 2.63 & 69 & 2.36 & 1.53 & \\
\hline People pirate computer software to save money & 71 & 4.73 & 69 & 4.35 & $2.69 *$ & 0.45 \\
\hline People pirate computer software in case the computer programme is faulty & 71 & 2.85 & 68 & 2.79 & 0.28 & \\
\hline People pirate computer software because they think it is overpriced & 71 & 4.61 & 69 & 4.12 & $3.65^{* *}$ & 0.62 \\
\hline People pirate computer software because they find it an enjoyable activity & 71 & 2.69 & 69 & 2.60 & 0.49 & \\
\hline $\begin{array}{l}\text { People pirate computer software because it increases their status in the } \\
\text { community }\end{array}$ & 71 & 2.31 & 69 & 2.41 & -0.54 & \\
\hline People pirate computer software because it increases their power & 71 & 2.54 & 68 & 2.38 & 0.82 & \\
\hline $\begin{array}{l}12 \text { People pirate computer software because they think someone else will } \\
\text { pirate software for them at a later date }\end{array}$ & 71 & 3.15 & 69 & 2.51 & $4.40^{* *}$ & 0.74 \\
\hline $\begin{array}{l}13 \text { People pirate computer software because someone has pirated } \\
\text { software for them in the past and they are returning the favour }\end{array}$ & 71 & 3.15 & 69 & 2.62 & $4.40^{* *}$ & 0.74 \\
\hline \multicolumn{7}{|l|}{ Deterrents } \\
\hline $\begin{array}{l}\text { People do not pirate computer software because they are scared of getting } \\
\text { caught }\end{array}$ & 71 & 3.04 & 69 & 3.14 & -0.52 & \\
\hline $\begin{array}{l}\text { People do not pirate computer software because the punishments are } \\
\text { harsh }\end{array}$ & 70 & 2.46 & 69 & 2.91 & $-2.61^{*}$ & 0.44 \\
\hline $\begin{array}{l}\text { People do not pirate computer software because they are worried what } \\
\text { people at work would think }\end{array}$ & 70 & 2.59 & 68 & 2.40 & 0.51 & \\
\hline $\begin{array}{l}\text { People do not pirate computer software because they are worried what } \\
\text { people in their community would think }\end{array}$ & 70 & 2.37 & 67 & 2.30 & 0.46 & \\
\hline $\begin{array}{l}\text { People do not pirate computer software because they would be unhappy } \\
\text { with their own behaviour if they pirated software }\end{array}$ & 69 & 2.72 & 69 & 2.57 & 0.78 & \\
\hline
\end{tabular}

${ }^{*} P<.05 .,{ }^{* * P}<.01$

Table 6: Correlations between primary independent variables and piracy intentions

\begin{tabular}{llcccc}
\hline & Country & $\mathbf{N}$ & $\mathbf{r}$ & $\boldsymbol{P}$ value & Z-score \\
\hline Attitudes & South Africa & 68 & 0.75 & $<.01$ & 2.26 \\
Social norms & Zambia & 66 & 0.61 & $<.01$ & \\
& South Africa & 69 & 0.61 & $<.01$ & 0.18 \\
Self-efficacy & Zambia & 67 & 0.59 & $<.01$ & \\
\multirow{3}{*}{ Moral disengagement } & South Africa & 69 & 0.53 & $<.01$ & 0.23 \\
Zncentives & Zambia & 68 & 0.50 & $<.01$ & \\
& South Africa & 69 & 0.48 & $<.01$ & 1.72 \\
Deterrents & Zambia & 61 & 0.21 & NS & \\
& South Africa & 69 & 0.06 & NS & -0.29 \\
& Zambia & 67 & 0.11 & NS & \\
& South Africa & 69 & -0.37 & $<.01$ & 0.99 \\
& Zambia & 64 & -0.21 & NS & \\
\hline
\end{tabular}

Table 8: Multiple regression of the independent variables onto piracy intention (Zambia)

\begin{tabular}{lccc}
\hline & $\boldsymbol{B}$ & $\boldsymbol{R}^{2}$ total & $\boldsymbol{F}$ \\
\hline Social norms & 0.47 & 0.47 & $46.11^{* *}$ \\
Attitudes & 0.40 & 0.58 & $14.25^{* *}$ \\
Self-efficacy & 0.27 & 0.64 & $8.23^{* *}$ \\
\hline
\end{tabular}

${ }^{* * P}<.01$
Table 7: Multiple regression of the independent variables onto piracy intention (South Africa)

\begin{tabular}{lccc}
\hline & $\boldsymbol{\beta}$ & $\boldsymbol{R}^{2}$ total & $\boldsymbol{F}$ \\
\hline Attitudes & 0.50 & 0.57 & $22.07^{* *}$ \\
Social norms & 0.39 & 0.64 & $12.55^{* *}$ \\
Self-efficacy & 0.23 & 0.66 & $4.98^{*}$ \\
\hline
\end{tabular}

${ }^{*} P<.05$. ${ }^{*} P<.01$

internal motives to pirate software but were also more likely to perceive that the punishments for getting caught pirating software were harsh [Table 4]. Respondents in the South African sample were more likely to pirate software if they felt that software was overpriced or they could save money. Similarly, Gupta et al. (2004) and Al-Rafee and Cronan (2006) found that students often cite monetary loss as a motivator to pirate. Similarly to Al-Rafee and Cronan (2006), the South African sample also indicated that they were more likely to pirate software if there was some reciprocal exchange (i.e. that someone else would copy something for them).

The only significant difference on the points of moral disengagement was at the point of the actual behaviour, where the South African sample was more likely to morally 
disengage than the Zambian sample. This would suggest that the South African sample would actually be more likely to engage in software piracy behaviour because of their higher propensity to morally distance themselves from this illegal activity. The lack of a significant difference in the software piracy intentions is surprising given the large disparity in software piracy rates as provided by Business Software Alliance (2011). This suggests either that students are not the primary perpetrators of software piracy in Zambia and South Africa, that the respondents were not being honest in admitting their intentions (a possibility given the relatively severe punishments for software piracy), that intentions are not directly related to behaviour, or that the Business Software Alliance's (2011) estimates are not accurate. It must also be noted that the South African sample were significantly more experienced with computers than the Zambian sample (i.e. significantly many more years using a computer and significantly more time online per week). It might be that the South African sample therefore had greater opportunities to pirate software and higher skill levels with computers to enable illegal copying.

\section{Comparing the relationships with software piracy} intentions for the Zambian and South African samples

Following Swinyard et al.'s (1990) results regarding attitudes in different cultures, the Z-test results demonstrated that none of the relationships with intentions were significantly different between the two samples. This supports Bandura's (1986) contention that SCT is not sensitive to cultural differences. The strong positive correlations between attitudes and intentions (in both samples) are consistent with Peace et al. (2003) and Gupta et al. (2004). Similarly, the strong, positive relationships between self-efficacy and intentions were supported by Kuo and Hsu (2001) and Peace et al. (2004). Limayem et al. (2004), Al-Jabri and Abdul-Gader (1997) and Peace et al. (2003) all found that the social context was significantly related to software piracy intentions. While incentives were positively correlated with intentions and deterrents were negatively correlated with intentions, these correlations were not significant for the Zambian sample (and for incentives in the South African sample). It is possible that deterrents moderate the relationship between incentives and behaviour (i.e. not as predictors of intentions, but rather moderating actual behaviour).

\section{Comparing predictors of software piracy intentions}

In both samples attitudes, social norms, and self-efficacy were the only three significant predictors of software piracy intentions, explaining an impressive proportion of the variance $166 \%$ for the South African sample and $64 \%$ for the Zambian sample) in software piracy intentions. The slight differences in the ordering of these three predictors suggest that social norms were slightly more important in the Zambian sample in influencing software piracy intentions. This result provides partial support for Traphagan and Griffith's (1998) emphasis on the importance of cultural (social) norms. In essence, though, the presence of attitudes, social norms, and self-efficacy in the multiple regression mirrors the theory of planned behaviour (Ajzen, 1991), with attitudes, social norms, and perceived behavioural control as the primary antecedents of intentions. Peace et al. (2003) also found good support for these three variables in predicting software piracy intentions. The fact that moral disengagement did not emerge as a significant predictor of software piracy intentions was surprising, particularly as Cronan and Al-Rafee (2008) found that moral obligations were a significant predictor of intentions. It could be that there are other variables that intervene between moral justification (one aspect of moral disengagement) and software piracy intentions. For example, LaRose and Kim (2007) found that deficient self-regulation was an important predictor of intentions in their model of illegal music downloading. Alternatively, moral disengagement mechanisms may be unnecessary, since respondents in this sample do not intend to pirate software.

Even though Siponen and Variainen (2005) cite situational factors as being important in predicting software piracy behaviour, incentives and deterrents were not significant predictors of software piracy intentions in either sample. Bandura (1986) contended that legal sanctioning was an ineffective means of controlling behaviour. This might explain why software piracy is apparently rampant in Zambia despite external deterrents (i.e. legislation) to curb it. South Africa has far more sophisticated intellectual property laws than Zambia and yet the Zambian sample was significantly more likely to perceive the punishments to be an important deterrent to software piracy than the South African sample. As the International Data Corporation (2009) argues, this could be because the policing of these laws is ineffectual in South Africa.

\section{Limitations}

The primary limitation is that the generalisability of these results is limited. This study looked at only one university in each country and at students studying towards an Economics major. These results may not apply to students at other universities, studying towards other majors, or to people who are not students. Given the concern about the reliability of the Business Software Alliance's (2011) data (see Png, 2010), there is reason to be cautious about the choice of countries for comparison (i.e. as countries with relatively high and low software piracy rates). Second, this study did not collect data on past software piracy behaviours. We cannot therefore conclude that the software piracy intentions lead directly to software piracy behaviour. Third, the study design was cross-sectional, 
making it difficult to determine the structural causality of a number of the variables in Bandura's (1986) SCT. Fourth, no measures of national culture were available for the Zambian sample. It is possible that national culture may have a greater influence on software piracy behaviour than the SCT variables.

\section{Recommendations for future research}

The most obvious recommendation for future research would be to include a measure of past behaviour. Further, in order to assess whether software piracy intentions lead to actual software piracy behaviour a longitudinal study would be necessary. It would also be interesting to assess a structural model of the SCT components (e.g. determine where incentives and deterrents are most likely to make an impact). This would require a larger sample size to enable the assumptions of structural equation modelling to be met. Finally, we would recommend studies which would enable a direct comparison of cultural elements to be made, perhaps by comparing countries which have systematic measures of Hofstede's culture dimensions.

\section{CONCLUSION}

South Africa and Zambia have radically different piracy rates (35\% and $82 \%$ respectively), suggesting that there are local contextual factors (e.g. culture and climate) that account for these differences. This study used Bandura's SCT (1986) as a theoretical framework by examining attitudes, moral disengagement, self-efficacy, perceptions of the social context (social norms, incentives and deterrents), and software piracy intentions. For hypothesis 1 there were no statistical differences in software piracy intentions: the South African sample had more positive attitudes and more favourable perceptions of social norms towards software piracy. The South African sample also reported extrinsic incentives (i.e. monetary reward and reciprocal exchange) as more important incentives to pirate software than the Zambian sample. Respondents in the Zambian sample reported the pleasure they derive from pirating as a stronger incentive and the threat of harsh punishment as a stronger deterrent. In support of hypothesis 2 there were no differences between the two samples in terms of the relationship between attitudes, social norms, and self-efficacy and piracy intentions. In support of hypothesis 3, while a slightly different predictor pattern emerged for predicting software piracy intentions, these were not statistically different by country. Due to the high proportion of variance explained by attitudes, social norms, and self-efficacy, it is concluded that SCT is an equally good theoretical model for predicting software piracy intentions in both countries.

\section{ACKNOWLEDGMENTS}

This work is based upon research funded by the National Research Foundation (NRF) of South Africa. Opinions expressed in this article and conclusions arrived at are those of the authors and should not necessarily be attributed to the NRF.

\section{REFERENCES}

Ajzen, I. (1991). The Theory of Planned Behavior. Organizational Behavior and Human Decision Processes, 50, 179-211.

Al-Jabri, I and Abdul-Gader, A. (1997). Software copyright infringements: An exploratory study of the effects of individual and peer beliefs. Omega International Journal of Management Science, 25, 335-344.

Al-Rafee. S. and Cronan, T.P. (2006). Digital piracy: Factors that influence attitude toward behavior. Journal of Business Ethics, 63, 237-259.

Bagchi, K., Kirs, P. and Cerveny, R. (2006). Global software piracy: Can economic factors alone explain the trend? Communications of the ACM, 49, 70-76.

Ballantine, P. (2000). Examining the effects of culture on perceptions of moral intensity: A comparison of future marketers from Malaysia and New Zealand. In the Proceedings of AMZMAC 2000 visionary marketing for $21^{\text {st }}$ Century. Griffith University Gold Coast, Queensland, Australia, 28 November -1 December, 2000.

Bandura, A. (1986). Social foundations of thought and action. A social cognitive theory. Englewood Cliffs, NJ: Prentice-Hall.

Bandura, A. (2004). Health promotion by social cognitive means. Health Education and Behavior, 31, 143-164.

Bandura, A. (2006). Toward a psychology of human agency. Perspectives on Psychological Science, 1, 164-180.

Bandura, A. Barbaranelli, C., Caprara, G.V. and Pastorelli, C. (1996). Mechanisms of moral disengagement in the exercise of moral agency. Journal of Personality and Social Psychology, 71, 364-374.

Business Software Alliance (2011). Eighth annual BSA-IDC global software piracy study. May, 2011. http://portal.bsa.org/globalpiracy2010/. Accessed on 20 May 2011.

Chang, M.K. (1998). Predicting unethical behavior: A comparison of the theory of reasoned action and the theory of planned behavior. Journal of Business Ethics, 17, 1825-1834.

Cho, K. and Eining, M. (1997). Information ethics: An empirical investigation of Korea and the United States. In Proceedings of the American accounting association.

Crittenden, W., Roberston, C. and Crittenden, V. (2007). Hard facts about software piracy. Business Strategy Review, 18, 29-33

Cronan, T.P. and AI-Rafee. S. (2008). Factors that influence the intention to pirate software and media. Journal of Business Ethics, 78, 527-545.

Eining, M.M. and Christensen, A.L. (1991). A psycho-social model of software piracy: The development and test of a model. In R. Dejoie, G. Fowler and D. Paradice (Eds.). Ethical issues in information systems (pp. 182-188). Boston, MA: Boyd and Fraser.

Glass, R.S. and Wood, W.A. (1996). Situational determinants of software piracy: An equity theory perspective. Journal of Business Ethics, 16, 1189-1198.

Gopal, R.D. and Sanders, G.L. (1998). International software piracy: an analysis of key issues and impacts. Information Systems Research, 9, 380-397.

Gopal, R.D. and Sanders, G.L. (2000). Global software piracy: you can't get blood out of a turnip. Communications of the ACM, 43, 83-89.

Gupta, P. B., Gould, S. I. and Pola, B. (2004). To pirate of not to pirate: a comparative study of the ethical versus other influences on the consumer's software acquisition-mode decision. Journal of Business Ethics, 55, 255-274.

Higgins, G.E. and Makin, D.A. (2004). Does social learning theory condition the effects of low self-control on college students' software piracy? Journal of Economic Crime Management, 2, 1-22.

Hinduja, S. (2003). Trends and patterns among online software pirates. Ethics and Information Technology, 5, 49-61.

Hinduja, S. (2007). Neutralization theory and online software piracy: An empirical analysis. Ethics and Information Technology, 9, 187-204.

Hinduja, S. (2008). Deindividuation and internet software piracy. Cyber Psychology and Behavior, 11, 391-398. 
Huck, S.W. (2004). Reading statistics and research (4th ed.). Boston, United States of America: Pearson Education.

Husted, B.W. (2000). The impact of national culture on software piracy. Journal of Business Ethics, 26, 197-211.

International Data Corporation (2009). White Paper: How to reduce software piracy in the Middle East and Africa: The case of South Africa. November, 2009. http://www.bsa.org/country/Research\%20and\%20 Statistics/me/ /media/Files/White\%20Papers/ReducePiracyMEA/IDC_ ReducePiracyMEA_enZA.ashx. Accessed 4 January 2011:

Kini, R.B., Ramakrishna, H.V. and Vijayaraman, B.S. (2003). An exploratory study of moral intensity regarding software piracy of students in Thailand. Behavior and Information Technology, 22, 63-70.

Kovacic, Z. (2007). Determinants of worldwide software piracy. Proceedings of Informing Science and IT Education Conference, Ljubljana (pp. 128-150), Slovenia, 22-25 June 2007.

LaRose, R. and Kim, J. (2007). Share, steal or buy? A social cognitive perspective of music downloading. CyberPsychology and Behavior, 10, 267-277.

LaRose, R., Lai, Y.J., Lange, R., Love, B. and Wu, Y. (2005). Sharing or piracy? An exploration of downloading behavior. Journal of Computer-Mediated Communication, 11, 1-21.

Lending, D. and Slaughter, S.A. (1999). Understanding differences in ethical beliefs and behaviors toward software copying: the effects of organisation culture. Proceedings of the 1999 ACM SIGCPR Conference on Computer Personnel Research, pp. 253-260, April 8-10, 1999, New Orleans, USA.

Liang, Z. and Yan, Z. (2005). Software piracy among college students: A comprehensive review of contributing factors, underlying processes, and tackling strategies. Journal of Educational Computing Research, 33, 115-140.

Mishra, A., Akman, I. and Yazici, A. (2007). Organizational software piracy: An empirical assessment. Behavior and Information Technology, 26, 437-444.

Moores, T. and Dhillon, G. (2000). Software piracy: A view from Hong Kong. Communications of the ACM, 43, 88-93.

Peace, A.G., Galletta, D.F. and Thong, J.Y.L. (2003). Software piracy in the workplace: A model and empirical test. Journal of Management Information Systems, 20, 153-177.

Png, I.P.L. (2010). On the reliability of software piracy statistics. Electronic Commerce Research and Applications, 9, 365-373.

Rahim, M.M., Seyal, A.H. and Rahman, M.N.A. (2001). Factors affecting softlifting intention of computing students: An empirical study. Journal of Educational Computing Research, 24, 385-405.

Robertson, C.J., Gilley, K.M., Crittenden, V. and Crittenden, W.F. (2008). An analysis of the predictors of software piracy within Latin America. Journal of Business Research, 61, 651-656.

Seale, D.A., Polakowski, M. and Schneider, S. (1998). It's not really theft!: Personal and workplace ethics that enable software piracy. Behavior and Information Technology, 17, 27-40.
Shim, J.P. and Taylor, G.S. (1991). A comparative study of unauthorized software copying: Information systems faculty members' vs. practicing managers' perceptions. In R. Dejoie, G. Fowler and D. Paradice (Eds.). Ethical issues in information systems (pp. 189-198). Boston, MA: Boyd and Fraser.

Shin, S. K., Gopal, R. D. Sanders, G. L. and Whinston, A. B. (2004). Global software piracy revisited. Communications of the ACM, 47, 103-107.

Simpson, P.M., Bannerjee, D. and Simpson, C.L. (1994). Softlifting: A model of motivating factors. Journal of Business Ethics, 12, 431-439.

Sims, R.R., Cheng, H.K. and Teegen, H. (1996). Toward a profile of student software piraters. Journal of Business Ethics, 15, 839-849.

Siponen, M.T. and Variainen, T. (2005). Attitudes to and factors affecting unauthorized copying of software in Finland. Behavior and Information Technology, 24, 249-257.

Solomon, S.L. and O'Brien, J.A. (1991). The effect of demographic factors on attitudes towards software piracy. In R. Dejoie, G. Fowler and D. Paradice (Eds.). Ethical issues in information systems (pp. 168-181). Boston, MA: Boyd and Fraser.

Swinyard, W.R., Rinne, H. and Kau, K.A. (1990). The morality of software piracy: A cross-cultural analysis. Journal of Business Ethics, 9, 655-664.

Tang, J.H. and Farn, C.K. (2005). The effect of interpersonal influence on softlifting intention and behavior. Journal of Business Ethics, 56, 149-161.

Taylor, G.S. and Shim, J.P. (1993). A comparative examination of attitudes towards software piracy among business professors and executives. Human Relations, 46, 419-433.

Thong, J.Y.L. and Yap, C. (1998). Testing an ethical decision-making theory: The case of softlifting. Journal of Management Information Systems, 15, 213-237.

Traphagan, M. and Griffith, A. (1998). Software piracy and global competitiveness: Report on global software piracy. International Review of Law, Computers and Technology, 12, 431-451.

Triandis, C.H. (1977). Interpersonal Behavior. Monterey, California: Brooks/ Cole Publishing Company.

Van Belle, J., MacDonald, B. and Wilson, D. (2007). Determinants of digital piracy among youth in South Africa. Communications of the IIMA, 7, 47-63. Wang, F., Zhang, H., Zang, H. and Ouyang, M. (2005). Purchasing pirated software: An initial examination of Chinese consumers. Journal of Consumer Marketing, 22, 340-351.

Woolley, D.J. and Eining, M.M. (2006). Software piracy among accounting students: A longitudinal comparison of changes and sensitivity. Journal of Information Systems, 20, 49-63.

How to cite this article: Thatcher A, Matthews M. Comparing software piracy in South Africa and Zambia using social cognitive theory. Afr J Bus Ethics 2012;6:1-12.

Source of Support: Nil, Conflict of Interest: None declared

\section{AUTHORS}

Andrew Thatcher is Chair of Industrial/Organisational Psychology at the University of the Witwatersrand, where he is also Head of Department of Psychology. He is co-editor of the journal Ergonomics SA and assistant editor of Behaviour and Information Technology. He was the recipient of the Vice-Chancellor's Individual Teaching Award in 2004 and the University's e-Learning Award in 2007.

Mary Matthews was a master's student in the Department of Psychology at the University of the Witwatersrand at the time this study was conducted. She is now change management consultant for Accenture, based in Perth, Australia. 
Reproduced with permission of the copyright owner. Further reproduction prohibited without permission. 